\title{
A Semantic Account of the Stative Adverb Gap
}

\author{
Graham Katz \\ University of Tübingen \\ katz@sfs.nphil.uni-tuebingen.de
}

\begin{abstract}
It is argued that there is a surprising gap in the distribution of adverbial modifiers, namely that there are (practically) no adverbs that modify exclusively stative verbs. Given the general range of selectional restrictions associated with adverb/verb modification, this comes as a surprise. It is argued that this gap cannot be the result of standard selectional restrictions. An independently motivated account of the state-event verb contrast, in which state verbs are proposed to lack Davidsonian arguments is presented and argued to account for this stative adverb gap. Some apparent and real problems with the analysis are discussed.
\end{abstract}

\section{Introduction}

In early work on adverbial modification (Jackendoff 1972, Thomason and Stalnaker 1973), a fundamental distinction was drawn between S-adverbs and VP-adverbs. S-Adverbs such as probably and luckily appear relatively 'high' in the sentence and are ruled out sentence finally, while VP adverbs such as quickly and merrily appear 'lower' and are permitted sentence finally. Thomason and Stalnaker argued that S-adverbs and VP-adverbs are to be semantically distinguished. They claimed that $\mathrm{S}$-adverbs are propositional modifiers, while VP-adverbials are predicate modifiers; that is, the distinction between them is articulated in terms of the semantic objects that they modify. This semantic distinction was taken to account for some of the contrast between them, for example the fact that the S-adverb probably is acceptable in (1a) while the VP adverb quickly is ruled out in (1b).

(1) a. It was probably true that Bill kissed Jill.

b. *It was quickly true that Bill kissed Jill

One of the additional features that distinguishes S-adverbs from VP-adverbs is their selectivity.Generally speaking, S-adverbs are unrestricted with respect to the sentences they appear in. VP adverbs, on the other hand, are sensitive to the type of verb they modify. For example, although probably can appear in both (2a) and (2b), quickly can only appear in (3a).

(2) a. John probably loved Mary.

b. John probably kissed Mary.

(3) a. *John loved Mary quickly.

b. John kissed Mary quickly.

Thomason and Stalnaker noted that the type of verb-adverb selection illustrated in (3) could not be accounted for directly on their theory. Since love Mary is every much a predicate as kiss Mary is, there is no type-theoretic reason that (3a) should not be acceptable. Noting that 
such adverbs as quickly cannot modify stative verbs, they suggested that predicates be marked stative or eventive, and that VP adverb modification be made sensitive to this marking.

What Thomason and Stalnaker failed to note, however, was that adverbs select only against stative verbs and for eventive verbs. We don't, it seems, find adverbs that appear with stative verbs and but not with eventive verbs. That is, we don't find an adverb that fits the schema in (4).

(4) a. John loved Mary ADVERB.

b. *John kissed Mary ADVERB.

Adverbs are sensitive to the state/event contrast, but only in one way. If an adverb can felicitously modify a state verb, then it can also felicitously modify some event verb as well. This lexical gap, which we will call the stative adverb gap (SAG), is striking and should be accounted for by any theory of adverbial modification. ${ }^{1}$

In this paper, I discuss why the SAG is particularly problematic for the popular neoDavidsonian theories of sentence interpretation, of the type proposed by Bach (1986), Parsons (1990), Wyner (1994) and others. Then I present an alternative theory, which I call the classical Davidsonian theory, from which the SAG follows as a natural consequence.

\section{Neo-Davidsonian theory}

Neo-Davidsonian approaches to sentence semantics have grown in popularity since the early work of Bach (1981) and Parsons (1985). To review briefly, the fundamental neo-Davidsonian assumption is the following:

- Verbs denote predicates of eventualities (states or events)

This fundamental assumption about verbal meanings makes available a simple analysis of adverbial modification, which can be given in slogan form as follows (see Parsons (1990), Kamp and Reyle (1993), and Wyner (1994) for details):

- VP adverbs denote predicates of eventualities

- VP adverbial modification is (essentially) simple conjunction

Additionally many neo-Davidsonians adopt the view that verbs are related to their nominal arguments via Thematic roles relations. The example derivation in (5) illustrates the main features of the approach.

(5) a. John leave ; $\lambda$ e [leaving(e) \& Agent(e) $=$ John]]

b. slowly; $\lambda$ P $\lambda$ e $[\mathrm{P}(\mathrm{e}) \&$ slow $(\mathrm{e})]$

c. John left slowly ; $\exists$ e [leaving(e) \& Agent(e) $=$ John \& slow(e) \& e < now]

An untensed clause is (like a bare verb) interpreted as a predicate of events. Nominal arguments simply introduce further (conjunctive) information about participants in the event. VP-

I I have been made aware of two apparent counterexamples to this claim: still and no longer. These will be discussed towards the end of the paper. 
adverbs, while technically of a higher type, also introduce into the LFs underlying first order predication over events. This conjunctive modification accounts for the most obvious entailment facts about adverbial modification, namely that a modified sentence such as John left slowly entails the unmodified John left. (In many neo-Davidsonian accounts, tenses are also taken to add conjunctive information, locating the time at which the eventuality occurs with respect to the speech time, as we have indicated.)

Note that on the neo-Davidsonian account the contrast between S adverbs and VP adverbs then is not that between propositional modifiers and predicate modifiers, but rather between propositional modifiers and event predicates.

Besides the entailment facts just mentioned, the neo-Davidsonian approach articulates nicely the close relation many adverbs hold to their cognate adjectives. Given a semantics for nominals like John's leaving in which such expressions denote events (see Zucchi (1993)), the near-synonymy between (5c) and (6) is formally reconstructed.

John's leaving was slow

Modulo definiteness (6) and (5c) have the same meaning, and on the neo-Davidsonian view they are given the same semantic analysis. The underlying predicate slow is taken to be the common semantic element, which is predicated of the underlying event introduced by leave. ${ }^{2}$

A further appealing innovation of the neo-Davidsonian approach, one that is central to our concerns here, is the treatment of Vendler/Dowty-type aspectual classes (Vendler 1967; Dowty 1979). Since (all) verbs are interpreted as predicates of eventualities, the distinctions among the aspectual classes can be characterized in terms of properties of these eventuality predicates. The most straightforward characterization is the following (taken from Bach (1986)):

- State verbs are those verbs that denote predicates of states.

- Activity verbs are those verbs that denote predicates of homogeneous events.

- Accomplishment verbs are those verbs that denote predicates of non-homogeneous events.

- Achievement verbs are those verbs that denote predicates of momentary events.

Given that adverbs, like verbs, are predicates of events, we might also classify adverbs in terms of the character of the underlying eventuality predicate which they denote. Much as we characterize the verbs run and walk as activity verbs because they are homogenous predicates of events, we might characterize continually as an activity adverb, because it too is a homogeneous predicate of events.

On the neo-Davidsonian theory, then, a stative adverb would simply be an adverb that applies only to states. While it is certainly not a prediction of the neo-Davidsonian perspective that such adverbs should exist, the theory also doesn't rule them out. For the neo-Davidsonian the SAG is merely an accidental lexical gap, and a somewhat surprising one, considering the central role that the state-event contrast plays in the verbal domain (see Dowty 1979 or Hinrichs 1985 Ch. 1, Katz 1995).

2 In other work (Katz 1999), I have suggested that accounting for this fundamental parallelism in a compositional way in a neo-Davidsonian framework is not at all straightforward, if it is even possible. 


\section{Verb-Adverb Selection and the Stative Adverb Gap}

Verb-adverb selection is a complex phenomenon (Jackendoff 1972, Rochette 1990). It is clear that certain adverbs appear with some types of verbs but not with other types of verbs. This is illustrated by the pairs in (7) - (9).

(7) a. Austin tripped accidentally.

b. ??Austin wrote his book accidentally.

(8) a. Melanie talked endlessly.

b. ??Melanie finished her book endlessly.

(9) a. Steve finished his book quickly.

b. ??Steve slept quickly.

Intuitively, the infelicity of (7b), ( $8 b)$ and (9b) seems somehow to be tied to an incompatibility between the verbal and adverbial meanings. In (7b), for example, the fact that for an event to be accidental it must be done without intent seems to conflict with fundamental intentionality of an event of book-writing. You just can't write a book accidentally.

The neo-Davidsonian approach, of course, gives us a way of making this intuition precise. On this approach one can simply say that verb-adverb selection is a reflection of the compatibility or incompatibility of the event predicates. Infelicity results from attempting to apply two incompatible predicates to the same event. In other words, verb-adverb selection is essentially the same phenomenon as classical "selectional restrictions" of the type illustrated in (10) (Chomsky 1965; Katz and Fodor 1964).

(10) a. ??My shirt wants to go home.

b. ??My thoughts were very tall.

Just as there is an incompatibility being a shirt and being an object with desires (at least given our normal everyday world), and between being tall and being a thought, there is an incompatibility between being an event of book-writing and it being an accidental event. In both the classical cases and the verb-adverb cases it is incompatible co-predication that is the fundamental source of the infelicity.

We might, in fact, derive the infelicity from Grice's (Grice 1975) Maxim of Informativeness. We would say that a predicate $Q$ violates the selectional restrictions of a predicate $P$ iff it is not possible that any individual to satisfy both $\mathrm{P}$ and $\mathrm{Q}$. If it is not possible for an individual to be both $\mathrm{P}$ and $\mathrm{Q}$, it is uninformative to claim that there is an $\mathrm{x}$ such that $\mathrm{P}(\mathrm{x})$ and $\mathrm{Q}(\mathrm{x})$, since such a claim would necessarily be false. This uninformativeness is what gives rise to the infelicity we feel in the case of selectional restrictions. (Naturally, I am ignoring the fact that in typical cases it is the presuppositions associated with one or the other of the predicates that is incompatible with the other predicate, but that need not concern us.) A sentence such as (11), then, gives rise to a selectional-restriction violation because the predicate bachelor, meaning unmarried man, is not compatible with the property of having a wife (which is the presupposition associated with the use of the possessive in (11)).

(11) ??The bachelor's wife was charming. 
Note that when selectional restrictions are violated, speakers often attempt to reinterpret the sentence so as to "save" the utterance. In the case of (11) a hearer might reinterpret the phrase the bachelor as making reference to a man who, while married, has many other features of bachelorhood. This process of reinterpretation is also evident in such sentences as (7b), (8b) and ( $9 \mathrm{~b})$. In attempting to "save" (7b), for example, we might reinterpret accidentally to mean something like effortlessly and quickly, which would then be compatible with book writing. Or we might interpret finish in (8b) to mean work on finishing. That this kind of reinterpretation is evident in the both the case of verb-adverb selection and of subject-predicate selection is one indication that they are one and the same phenomenon.

At first glance, of course, it seems that an account of the SAG that appeals to this kind of verb-adverb selection would be the most straightforward and obvious account there could be: Adverbs that don't appear with state verbs are simply adverbs that happen to select for dynamic or agentive properties of an eventuality. The fact that (12) is infelicitous, then, is not a grammatical fact, but simply another example of the kind of verb-adverb selection we saw at work in (7) - (9).

\section{??Peter knew Mary gently.}

The reason (12) is odd is simply that gently, being a manner of action adverb, is a predicate that holds of an eventuality if and only if the manner in which the eventuality was acted out was gentle. Know, on the other hand, is a predicate of states. States, being static do not have manners of being acted out, and so it is not possible for gently and know to apply to the same eventuality.

This much is fine. The problem is that this kind of account only explains why certain adverbs do not combine with state verbs. It doesn't account for the stative adverb gap, that is we don't have an explanation for why there are no adverbs that combine with state verbs but not event verbs. In fact, we are stuck thinking there should be some adverbs out there that are formally like gently, in that they are predicates of eventualities, except that they select for nondynamic, non-agentive eventualities. This kind of gap is, in fact, not at all characteristic of selectional restrictions as we know them from the classical subject-predicate case.

Typically, selectional restrictions are symmetrical. That is, if $\mathrm{P}$ and $\mathrm{Q}$ are incompatible predicates, we can usually find a $\mathrm{P}^{\prime}$ and a $\mathrm{Q}^{\prime}$ such that $\mathrm{P}$ and $\mathrm{Q}^{\prime}$ are compatible, $\mathrm{P}^{\prime}$ and $\mathrm{Q}$ are compatible, and $\mathrm{P}^{\prime}$ and $\mathrm{Q}^{\prime}$ are incompatible. Consider the case in (13):

??My thoughts are tall.

Here $\mathrm{P}$ is being a thought and $\mathrm{Q}$ is being tall. These predicates are incompatible. But of course we can find both a $\mathrm{P}^{\prime}$ and a $\mathrm{Q}^{\prime}$ that result in acceptable variants, namely being $a$ mountain and being confused.

(14) a. The mountain is tall.

b. My thoughts are confused.

The point is this: We don't have just predicates that select for mental objects to the exclusion of, say, physical objects, we also have predicates that select for physical objects to the exclusion of mental objects. It might seem that we are simply commenting on the accidental properties of the lexicon. I think, however, that there is good reason to expect selectional restrictions exhibit this kind of symmetry. 
Selectional restrictions reflect the semantic compatibility between predicates of different syntactic category. In the classical case, this is compatibility between nouns and verbs or adjectives. Since the kind of compatibility we are concerned with here is purely "real world" compatibility, and there is no a priori association of classes of meanings (beyond semantic type) to syntactic categories, we expect that the classes of compatible (and incompatible) predicates should be distributed evenly among the syntactic categories. If two syntactic categories are of the same semantic type, then for any lexical elements from one category, there should be an element from the second that denotes a compatible predicate and one that denotes an incompatible predicate. If there are syntactic contexts in which the semantic combination rule for these categories is conjunctive, then selection restriction violations will exhibit paradigmatic symmetry. We might, then, take symmetry, alongside reinterpretation, to be a test for whether a particular infelicity is due to selectional restriction violations or something else.

Paradigmatic symmetry, of course, is exactly what is missing in the case of adverbial selection of stative verbs. We only have adverbs that select for event verbs to the exclusion of state verbs and not adverbs that select for state verbs to the exclusion of event verbs. Interestingly, if we leave stative verbs aside, we see that other types of verb-adverb selection do exhibit symmetry. That is, we find such paradigms as (15).

(15) a. ??John slept quickly.

b. John ran quickly.

c. John slept deeply

d. ??John ran deeply.

The fact that in the case of adverbial modification of stative verbs there is no paradigmatic symmetry, suggests to me that the SAG has a grammatical basis. In the following section I will propose that there is a grammatical distinction between event verbs and state verbs from which the SAG follows as a natural consequence.

\section{Accounting for the Stative Adverb Gap}

An often-expressed intuition is that the crucial distinction between states and events is that states simply don't have many properties. Events are much more interesting, and therefore there is much more to be said about them. Because of this, they are compatible with a larger class of predicates, and thus event verbs combine felicitously with more adverbs then state verbs do. To analogize, if events are like paintings, states are like blank canvases. Both have dimensions, but for a canvas, that is about all there is to it, whereas for a painting we can talk about the theme of the painting, the shading, the use of light and so on. In the case of states and events, while we can talk about the dimensions of both (i.e. their spatio-temporal properties), for events there is simply so much more; we can also talk about their manner, their speed and their causes and effects and their purposes.

I find this intuition compelling, and take it to show us is that events and states are not two classes of the same type of object, as the neo-Davidsonian would have it, but rather that events are highly articulated things of which states are the most simple form. In the next section, I give this intuition formal expression and show how this formal mechanism accounts for the stative adverb gap. The lack of stative adverbs, then, is not an accidental property of the lexicon, but in fact follows from the character of the state/event distinction. 


\subsection{The State/Event Distinction}

In Davidson's (1967) paper he suggests that "fact" verbs be distinguished from event verbs in that they lack an extra event argument. Davidson's tentative suggestion has been adopted by a number of researchers and pushed into service to account for some of the more well-known state/event contrasts (see Galton (1984), Löbner (1988), Sandstrøm (1993), and Katz (1995)). The basic idea is that state verbs are distinguished from event verbs by the absence of a Davidsonian argument. The event sentence (16a) and the state sentence (16b), then, have different logical representation, as shown in (17).

(16) a. Sandy kissed Kim.

b. Sandy liked Kim.
a. $\exists$ e $[\mathrm{kiss}(\mathrm{e}, \mathrm{Sandy}, \mathrm{Kim})]$
b. like(Sandy,Kim)

On this approach, as we see, state verbs are of a different logical type than are event verbs with the same number of NP arguments. There are two things to note: First, the fact that there are no underlying states in the logical form for (16b) requires us to adopt an "ordered argument" account of the verb-argument relations (Dowty 1991), at least for stative sentences. For uniformity, it seems sensible to adopt such an account generally. Secondly, once existential closure has applied to the event sentence, state sentences and event sentences are of the same logical type. It is in this sense that event sentences are also like state sentences but are simply more articulated.

General discussion of the empirical advantages of this approach to the state/event contrast, which I will call the "classical" Davidsonian approach, would take us too far afield here (but see, Katz (1997); Katz (2000)). Let us just take a single example. Consider the fact, illustrated in (18), that state verbs cannot appear as bare infinitive complements of perception verbs.
(18)
a. Peter saw Sue leave.
b. *Peter saw Sue wear a coat.

It is standardly assumed that these complements are interpreted as indefinite descriptions of the eventuality introduced by the complement verb (Higginbotham 1983). State verbs such as wear in wear a coat, which clearly would refer to perceivable states, are for some reason prohibited in this context. This prohibition follows naturally if these verbs simply lack an eventuality argument. ${ }^{3}$ The grammatical mechanism which turns bare infinitivals into eventuality descriptions is simply unable to apply to them. A number of event/state contrasts in the domain of nominalization, sentential anaphora, and tense interpretation are likewise amenable to classical Davidsonian analyses. And, of course, my claim is that the stative adverb gap is as well.

In the next section I present the outlines of my particular classical Davidsonian account of sentence interpretation. I present several details which are not, in fact, relevant to the treatment of adverbials, but which I think, aid in the understanding of the mechanism.

3 Higginbotham himself makes a similar proposal. Unfortunately he confuses the state/event contrast with the stage-level/individual-level contrast (Carlson 1977). That such stage-level statives as wear a coat are prohobited is something his proposal does not explain. 


\subsection{Classical Davidsonianism}

Since both state sentences and event sentences have temporal components to their semantics, I will assume that both saturated state verbs and saturated event verbs are predicates of times. Tenses will apply to these time predicates to yield propositional meanings. The "upper" part of the system, then, is fairly standard:

- Sentence meanings are propositions

- Fully saturated verbs are properties of times

- Tenses are functions from predicates of times to propositions

We will distinguish fully saturated verbs from "nominally" saturated verbs. Nominally saturated verbs are those that have all their nominal arguments, but may be missing an underlying implicit argument. The basic assumption of the classical Davidsonian approach is that eventive verbs can be nominally saturated without being fully saturated. The basic difference between state verbs and event verbs then is that:

- Nominally saturated state verbs are properties of times.

- Nominally saturated event verbs are properties of events.

The difference between state sentences and non-state sentences, then, appears "below" the tenses and "above" the VP. Following Klein (1994), Kratzer (1998), and others I assume the existence of two aspectual operators that turn predicates of events (nominally saturated event verbs) into predicates of times. These are the operators PERFECTIVE and PROGRESSIVE. If we make the further natural assumption that these operators are syntactic heads, this semantic contrast between state sentences and event sentences receives expression in the syntax, as illustrated in (19):

(19) a. [TP Sandy, $_{1}{ }_{\mathrm{T}}$ PAST [ ${ }_{\mathrm{Asp} P}$ PERFECTIVE [ ${ }_{\mathrm{vP}} \mathrm{t}_{1}$ kiss Kim $\left.\left.\left.]\right]\right]\right]$

b. [TP $\operatorname{Sandy}_{1}\left[{ }_{\mathrm{T}}\right.$ PAST [ $\left[\mathrm{vp}_{1}\right.$ like Kim $\left.\left.]\right]\right]$

Note that there is a mismatch between syntactic category and semantic type in the lexical vocabulary, since stative VPs and non-stative VPs are of different type. Stative VPs and eventive AspPs however share a semantic type: they are properties of times.

Our logical forms will be interpreted are respect to a structure $\langle\mathrm{D}, \mathrm{E}, \mathrm{T},<$, time-of $\rangle$, where $\mathrm{D}$ is the domain of individuals, among which $E$ is the subset of events, $T$ is the set of time intervals with ordering relation $<$. The function time-of takes an event and returns its run-time (this is Krifka's (1989) $\tau$ function).

The difference between the eventive kiss and the stative like is reflected by a difference in their lexical entries. Let us take a concrete example. Assuming that semantic combination is simply functional application we can, using the lexicon given below derive logical analyses of (19a) and (19b). Note that the first order variable $\mathbf{t}$ ranges over times, the variable e over events and the others over normal individuals.

$$
\begin{aligned}
& \text { kiss } ; \lambda \text { y } \lambda \times \lambda \text { e }[\operatorname{kiss}(\mathrm{e}, \mathrm{x}, \mathrm{y})] \\
& \text { like } \lambda \text { y } \lambda \text { x } \lambda \mathrm{t}[\text { like }(\mathrm{t}, \mathrm{x}, \mathrm{y})] \\
& \text { PAST } ; \lambda \mathrm{P} \exists \mathrm{t}[\mathrm{t}<\text { now } \& \mathrm{P}(\mathrm{t})] \\
& \text { PERFECTIVE } ; \lambda \mathrm{t} \exists \mathrm{e}[\mathrm{P}(\mathrm{e}) \& \text { time-of }(\mathrm{e}) \subset \mathrm{t}]
\end{aligned}
$$


The derivations, then, are as follows:

(20) a. Sandy kissed Kim.

b. [T Sandy $_{1}\left[{ }_{\mathrm{T}}\right.$ PAST [AspP PERFECTIVE $\left[{ }_{\mathrm{VP}} \mathrm{t}_{1}\right.$ kiss Kim ]]]]

c. $\exists \mathrm{t} \exists$ e [kiss(e,Sandy,Kim) \& time-of(e) $\subset \mathrm{t} \& \mathrm{t}<$ now $]$

(21) a. Sandy liked Kim.

b. [TP Sandy $_{1}\left[\mathrm{~T}\right.$ PAST [ ${ }_{\mathrm{VP}} \mathrm{t}_{1}$ like Kim $\left.\left.]\right]\right]$

c. $\exists \mathrm{t}[$ like $(\mathrm{t}, \mathrm{Sandy}, \mathrm{Kim}) \& \mathrm{t}<$ now $]$

We have, of course, simplified many of the less relevant issues, such as the treatment of tense. Nevertheless we get what we want: the claim on the one hand that there is a past time at which a kissing of Kim by Sandy occurred, and on the other the claim that there was a past time at which Kim liked Sandy.

There are a number of features of the tense-aspect system of English that fall out of the classical Davidsonian approach. Consider, for example the English progressive. If we make the natural assumption that it is taken to be the morphological expression of the operator PROGRESSIVE defined below, which is the natural dual of the PERFECTIVE operator, we can explain some of the most obvious properties that the English progressive exhibits: ${ }^{4}$

PROGRESSIVE $; \lambda \mathrm{t} \exists \mathrm{e}[\mathrm{P}(\mathrm{e}) \& \mathrm{t} \subset$ time-of(e)]

The progressive, then, is a function from event predicates to time predicates, intuitively the time at which that event was going on. Since the progressive is, effectively, a type shifter, it should not be able to apply either to state verbs, which are of the wrong type to act as 'input', or apply to its own output. This, of course, is exactly what we find to be the case:

(22) a. *John is owning a car.

b. *John is being kissing Mary.

Furthermore, the well-known "stativizing" effect of the progressive (Vlach 1981) also gets a fairly straightforward account in this framework, since formally the function PROGRESSIVE is a stativizing operator, in that it turns predicates of events into predicates of times.

\subsection{A Classical Davidsonian Account of Adverbial Modification}

Let us now look at how adverbs are treated. Like Thomason and Stalnaker's (1973) we distinguish adverbs that apply to the propositional content-probably, frankly from others. Furthermore, we distinguish temporal adverbials-yesterday, for an hour, on Sunday-from event adverbs -slowly, gently and the like. As would seem natural, temporal adverbs are taken to be predicates of times and event adverbs are predicates of events. For concreteness, here are some examples:

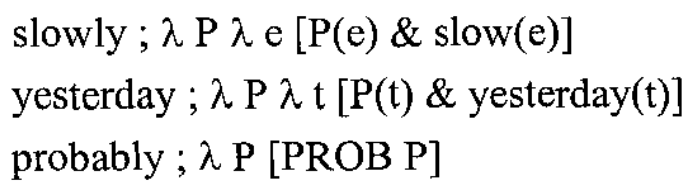

4 This semantics should, of course, be modalized. See Zucchi (1999) for a recent summing up of these issues. 
The intended interpretation of these underlying predicates is the following. When slowly applies to an event predicate it returns a predicate of slow events of the same kind, when yesterday applies to a temporal predicate, it returns a predicate of times that were yesterday, and when probably applies to a proposition $\mathrm{P}$ it returns a proposition that is true if it is probable that $P$.

The mechanism of adverbial modification adopted here is fairly simple. In contrast to syntactic theories such as that of Cinque (1999), I follow Wyner (1998) in assuming that the relative order of adverbials follows from principles of semantic composition. In short, adverbials adjoin freely to elements of the extended verbal projection, subject only to semantic compatibility. There are two kinds of semantic compatibility to be considered. Certain restrictions are type-driven: For example, S-adverbials apply to propositional meanings (and therefore adjoin quite high, say to the TP projection), while temporal adverbs are properties of times, and so adjoin either to AspectP or to stative VPs. Event adverbs only apply to eventive VPs. These adverbs are subject to the kind of selectional restrictions discussed in Section 3 (as, in fact, are the others, as we shall make clear subsequently).

Given a sentence such as (23a) in which there is a temporal adverb and an event adverb, the semantic combination is fairly straightforward. When everything functions as it should the event adverb combines with a compatible event predicate. An aspectual operator applies. And then a temporal adverb combines with the resulting time predicate. (It should be clear that type-theoretical restrictions rule out any other order of application of these two adverbs.) Finally a tense operator applies. The LF for (23a) is given in (23b) and the logical analysis in $(23 \mathrm{c})$.

(23) a. John left slowly yesterday.

b. [TP $\mathrm{John}_{1}\left[{ }_{\mathrm{T}}\right.$ PAST [AspP PERFECTIVE [ ${ }_{\mathrm{VP}} \mathrm{t}_{1}$ left slowly] yesterday]]]

c. $\exists \mathrm{t}[\mathrm{t}<$ now \& yesterday(t) \& $\exists[$ time-of(e) $\subset \mathrm{t} \&$ leave $(\mathrm{e}, \mathrm{John}) \&$ slow $(\mathrm{e})]]$

This system would have to be modified, of course, to be compatible with a syntactic approach to adverb placement: While the VP domain is taken to be the domain of event adverbs, TP domain the domain of S-adverbs, the domain of temporal adverbs is disjunctively described as either (eventive) AspP or (stative) VP. This problem is not evident if the composition system is entirely semantically driven.

\subsection{The SAG explained}

Like the restriction on stative progressives, the stative adverb gap is a direct consequence of the structure of the theory. Since adverbs such as slowly are, underlyingly, properties of events, it is clear that they cannot apply to stative VPs, which are properties of times. This is not fundamentally different from the claim that slowly, being a predicate of events, cannot apply to states. What makes the analysis interesting is that it rules out adverbs that apply exclusively to stative verbs.

Consider a potential adverb, state-adverb. To apply to stative VPs it must be of the same type as yesterday, that is, it must apply to properties of times. But if it is of this type then it could also apply to eventive AspectPs, which are also interpreted as properties of times. If the semantic account of adverbial distribution is correct, there should be no adverb that can apply to a stative VP without also being able to apply to an eventive AspectP.

From a semantic perspective an eventive predicate with an existentially closed event argument is of the same type as a stative predicate. Note that this is the fundamental claim of the classical Davidsonian account. And this is a claim which is independent of the particular 
implementation. Here we have assumed that stative predicates are simply predicates of times. There is very little evidence that they should be treated otherwise. But even if one were to adopt the view that stative predicates were predicates of underlying states, one could still maintain the classical Davidsonian perspective that existentially closed eventive predicates are of the same semantic type as nominally saturated state verbs. This would amount to claiming that the aspectual operators are functions from event predicates to state predicates. This alteration would not fundamentally undermine the results. As long as the fundamental insight that existentially closed event predicates are of the same type as state predicates, is maintained, it will be impossible for an adverb to exist that can combine with state predicates but is not of the right type to combine with existentially closed event predicates.

It should be noted that this does not quite mean that there cannot be adverbs that only appear in stative sentences. In fact, there are two adverbs that do: still and no longer. The existence of these two adverbs might at first seem to call into question not only the theory just proposed, but also the claim that there is a stative adverb gap to start with. As we will see in the next section, it is not as bad as all that.

\subsection{Still and no longer}

It is quite clear that still and no longer appear only in state sentences. The contrast between the eventives in (24) and the stative sentence in (25) makes this clear.

(24) a. *John kissed Mary no longer.

b. *John still wrote a book.

(25) a. John no longer owned a car.

b. John was still sick.

c. John was still kissing Mary.

d. John no longer worked in Stuttgart.

Note that these adverbs combine not only with lexical stative verbs such as own but also with derived statives such as the progressive in $(25 \mathrm{c})$ and the generic in $(25 \mathrm{~d})$. Semantically these adverbs are most naturally treated as temporal adverbials, since they seem intuitively to add information about the time for which the claim is taken to hold. If they are temporal adverbials it is not particularly surprising that they appear with state verbs. The question, then, would be why they don't seem to combine with event predicates, or, to be more precise, with eventive AspPs. I think there is very good reason for this, however. The reason being that it would violate the selectional restrictions of these adverbials.

Note that selectional restrictions of the standard kind are expected to apply just as much to predicates of times as they are to predicates of events. That is we expect there to be predicates of times that are simply incompatible with one another. In fact, this is a well known phenomenon: The classic cases of in an hour and for an hour, which select for different classes of temporal predicates, can be seen in this light.

(26) a. Peter ran the race in an hour.

b. *Peter owned a vacation house in the Alps in an hour.

(27) a. ??Peter ran the race for an hour.

b. Peter owned a vacation house in the Alps for an hour. 
Although both adverbials are predicates of times, because of the lexical semantics of temporal in and for the former is compatible with certain types of event verbs, while the latter is compatible with state verbs. The literature on this topic is extensive and varied (Dowty 1979, Hinrichs 1985, Krifka 1989, Moltmann 1991, Zucchi and White 1996). There is general agreement, however, that the contrast is due to purely temporal properties of the modifiers.

There is, then, normal selectional restriction, in the domain of temporal predicates. And as we have already discussed one of the features of selectional restrictions is that they are symmetric. So we expect there to be temporal modifiers that select for the temporal properties of event verbs to the exclusion of state verbs and temporal modifiers that select for the temporal properties of state verbs to the exclusion of event verbs. I would suggest, then, that in an hour is an example of the former, while still and no longer are examples of the latter. They are, then, temporal modifiers which happen to be compatible with the temporal properties of stative verbs but not with the temporal properties of eventive verbs.

In fact, when we consider what the semantics of still should look like, it is no longer surprising that it should select for state verbs. Intuitively still $P$ means that $P$ is true at some time $t$, that it was true at some time t' previous to that, and that it has been true at all the times in between $t$ and $t$ '. This is formalized in (28).

$$
\text { still } ; \lambda \mathrm{P}\left[\mathrm{P}(\mathrm{t}) \& \exists \mathrm{t}^{\prime}\left[\mathrm{t}^{\prime}<\mathrm{t} \& \mathrm{P}\left(\mathrm{t}^{\prime}\right) \& \forall \mathrm{t}^{\prime \prime}\left[\mathrm{t}^{\prime}<\mathrm{t}^{\prime \prime}<\mathrm{t} \rightarrow \mathrm{P}\left(\mathrm{t}^{\prime \prime}\right)\right]\right]\right]
$$

This analysis makes it quite clear why still selects for state verbs: it requires that the temporal predicate it applies to have the subinterval property. It is well known that this is one of temporal properties that state verbs have but event verbs lack. Similar comments hold in the case of no longer.

These are, so to speak, counterexamples that indeed prove the rule. Both event sentences and state sentences have components whose denotations are predicates of times. Given what we have said about selectional restrictions, it would be a surprise if the selectional restrictions that applied at this level were insensitive to the state/event contrast. In a sense, it is a prediction of the theory that there be temporal adverbials that are acceptable only in stative sentences as well as temporal adverbials that are acceptable only in event sentences. The existence of the adverbs still and no longer, then, is no problem at all. There is, however, one real difficulty to be addressed. I do so in the next section.

\section{A Problem with the Account: Stative 'Manner' Adverbs}

Given the above account, we would expect that stative verbs should only be modifed by temporal and propositional adverbs. This, however, is clearly not the case. There are a number of adverbs that combine felicitously with state verbs, but which would not normally be classified as temporal or propositional. Some examples are given in (29).

(29) a. Peter knew Maria well.

b. Lisa firmly believed that he was innocent.

c. Mary loves Max passionately.

I would hasten to add that these adverbs aren't exceptions to the SAG, as they all combine event verbs as well: 
(30) a. Peter played the song well.

b. Lisa held the door firmly.

c. Mary kissed Max passionately.

The adverbs in (29) do, however, behave very much like manner modifiers of event verbs, and that is what makes them troublesome. For example, as we mentioned above, one of the properties of manner adverbs is that they are closely related semantically to their adjectival cognates. This seems to be the case for the adverbs in (29) as well. Also in the case of state verbs can we derive a synonymous expression by nominalizing the verb and applying the cognate adjective to it. So (29c) seems synonymous with (31a) in much the way that (30c) is with (31b).

(31) a. Mary's love for Max is passionate.

b. Mary's kissing of Max was passionate.

One of the advantages of the neo-Davidsonian approach was that it made sense of this synonymy in a straightforward way. In both (30c) and (31b) the underlying predicate passionate applies to a kissing event. And on the neo-Davidsonain analysis of (29c) and (31a) the underlying predicate passionate is predicated of an underlying state, as in (32).

$\exists \mathrm{s}[$ love(s,Mary,Max) \& passionate(s)]

This treatment, of course, is inconsistent with the classical Davidsonian analysis, since the central assumption of that analysis is that state verbs do not have underlying eventuality arguments. The question, then, is whether the kind of modification illustrated in (29) 'manner' modification of state verbs - is enough like event modification to force us to reject the classical Davidsonian account.

There are two features of 'manner' modification of state verbs that lead me doubt that it really is parallel to event modification. First, the state verbs that can be modified by particular adverbs are lexical selected in a rather strict sense: love combines with passionately and know with well, but not the other way around, and neither of these adverbs combine with own. This contrasts sharply with the case of event verbs, where there is semantic but not lexical selection: speak, kiss, and even eat all combine with passionately and well. This may just mean that states are more finely grained than events, but alternately it might mean that we are dealing with phrasal idioms of a sort. Secondly, when they modify state verbs, these adverbs appear to be exclusively interpreted as degree modifiers. Although there is certainly some affective content associated with the word passionate, truth-conditionally (33a) means about the same as $(33 b)$.

(33) a. He loves her more passionately than she does him.

b. He loves her more than she does him.

This, again, is in stark contrast to event modification. (34a) is certainly not synonymous with (34b).

(34) a. He kissed her more passionately than she did him.

b. He kissed her more than she did him. 
We will discuss degree modification shortly. The point here is simply that in the case of event verbs, VP adverbs express a whole range of properties of events, from their auditory quality (loudly) to the mood of their agent (grumpily), while in the case of state verbs they seem only to indicate the degree to which an individual can be claimed to have a given property.

Even Parsons accepts that degree modifiers such as partway are not to be treated as event predicates. He points out that the typical pattern of entailments associated with event adverbs is not found in examples containing partway. (35a), for example, does not entail (35b).
a. Max filled the tank partway.
b. Max filled the tank.

When they modify event verbs, such modifiers seem to indicate the degree to which the underlying event is of the type described by the verb. In (35a), then, the claim being made is that there was an event of which Max was the agent that was partial a tank filling. This contrasts with the way degree modification of state verbs behaves. Consider the contrast in (36).
a. Max barely kissed Alissa.
b. Max barely knows Alissa.

In (36a) the claim is that the event wasn't much of a kiss, that is that there was an event and it was a kissing, but it only barely qualifies as one. Whereas in (36b), the claim seems to be that the degree to which Max knows Alissa is very small. To put things another way, on the one hand it is the degree to which a particular event qualifies as belonging to a certain type which is being measured, on the other hand it is the degree to which an individual can be said to have a certain property. Without introducing a full-blown semantics of degrees, we can see that this is, at least in form, what we expect from a classical Davidsonian account:
a. $\exists$ e [barely(kiss)(e,Max,Alissa)]]
b. barely(known)(Mary,Max)

The basic idea, then, is that the kind of adverbs that we see appearing with stative verbs but which clearly are not temporal or propositional modifiers are, in the end, predicate modifiers. It is at the level of predicates, I would suggest, that degree modification takes place. This accounts both for why it is available for state verbs as well as event verbs (one thing they have in common is that they are predicates).

Of course this is all rather sketchy, and how this semantic proposal is to be fleshed out is certainly the subject for additional research. Furthermore, how this proposal can be reconciled with the facts about nominalization is still somewhat of an open question. Clearly nominals such as his love for her must be given an analysis. Perhaps an analysis along the lines of the nominalized properties of Chierchia and Turner (1987) would be the most natural, taking these nominals to be terms that refer directly to properties. Once we take this step, however, we would seem to be left with questions to answer about the treatment of event nominals. Why, then, aren't they also to be treated as property nominalizations

An alternative is to treat the nominalization phenomenon as purely syntactic. I have only a speculation as to how this can be made to work: Under Marantz' (1999) theory of distributed morphology, lexical items enter the derivation without category specification, and that this is supplied later in the derivation. On this kind of theory, then, LOVE DEEP is a lexical idiom that enters the derivation as a unit and acquires the appropriate categorial status syntactically. 
When introduced in a nominal context it is pronounced deep love (as in his deep love for her), while in a verbal context it is pronounced love deeply. Such an account would have the advantage of making sense of the strict lexical selection we noted at the beginning of this section, since this kind of modification is, essentially, lexical. Furthermore the distinction between predicate modifiers, which are lexically introduced, and event modifiers, which are not, is made overt in the syntax.

I do not find this discussion entirely satisfying, however, not because I think it points to a particular strength of the neo-Davidsonian approach over the classical Davidsonian, but rather because I fear that it indicates that the Davidsonian notion of event modification as simple copredication, is so simple as to be wrong. It is clear that there are any number of VP modifiers that are event modifiers, but which, semantically don't look at all like event modifiers. In (38a) it is not the devouring event that is hungry, but the lion. In (38b) it is not the event that is temporary, but rather Peter's absence from the university.

(38) a. The lion devoured the deer hungrily.

b. Peter left the university temporarily.

What these and many other examples illustrate is that event co-predication, of the sort argued for by Davidson, is really only one of a number of kinds of modification available, perhaps it is even simply a family of other more specific kinds of modification. Degree modification is another type (or family of types). Trying to make all kinds of VP modification fit into the same mold by introducing an underlying argument for every element that needs to be modified may seem good when the number of kinds of such elements is small. But when the number starts to grow the plausibility (not to speak of the tractability) of such an analysis becomes questionable. The problems I hope to have raised for treating VP adverbial modification of state verbs in a neo-Davidsonian fashion seems, then, to be only part of a more general reconsideration of how the fine structure of adverbial modification should be addressed.

\section{Conclusion}

In summary, then, I have claimed that there is a missing class of adverbs, namely adverbs that select only for state verbs, whose non-existence is not accounted for in the literature. I have further argued that this stative adverb gap (SAG) is not plausibly accounted for on the basis of adverbial selectional restrictions. I suggest that the gap is far too systematic to be accidental. The central claim of the paper, then, is that the SAG arises from the structure of the theory of sentence interpretation. I then laid out the bare bones of a particular theory, which I called the classical Davidsonian theory, in which the event state contrast is analyzed in terms of the presence or absence of an underlying eventuality argument. State verbs do not have such arguments. Further adopting a semantic theory of adverbial modification, I showed how the SAG follows from the classical Davidsonian assumptions. Somewhat surprisingly, the potential counterexamples still and no longer were actually shown to vindicate the line of argument taken in the paper. Finally we were perplexed by the existence of adverbs that behave much as we might expect adverbial predicates of underlying states to behave. We have suggested that this is due to their being an instance of lexical predicate modification. Whether this can be made to work, and how this influences the analysis of eventive modification is left as an open question. 


\section{References}

Bach, Emmon (1981): On Time, Tense, and Aspect: An Essay in English Metaphysics. In: Peter Cole (ed.) Radical Pragmatics, 63-81. New York: Academic Press.

(1986): The Algebra of Events. Linguistics and Philosophy 9, 5-16.

Chierchia, Gennaro and Raymond Turner (1987): Semantics and Property Theory. Linguistics and Philosophy 11.

Chomsky, Noam (1965): Aspects of a Theory of Syntax. Cambridge, MA: MIT Press.

Cinque, Guglielmo (1999): Adverbs and Functional Heads: a Cross Linguistic Perspective. Oxford: Oxford University Press.

Davidson, Donald (1967): The Logical Form of Action Sentences. In: N. Rescher (ed.) The Logic of Decision and Action. Pittsburgh: University of Pittsburgh Press.

Dowty, David (1979): Word Meaning and Montague Grammar. Dordrecht, Holland: D. Reidel. (1991). Thematic Proto-Roles and Argument Selection. Language 67/3, 547-619.

Galton, Antony (1984): The Logic of Aspect. Oxford: Clarendon Press.

Grice, H. P. (1975): Logic and Conversation. In: Peter Cole and Jerrold Morgan (eds.) Syntax and Semantics 3: Speech Acts, 41-58. New York: Academic Press.

Higginbotham, James (1996): Perception Sentences Revisited. Oxford University, ms

Hinrichs, Erhard (1985):. A Compositional Semantcics for Aktionsarten and NP Reference in English. Ph. D. thesis, The Ohio State University.

Jackendoff, Ray (1972): Semantic Interpretation in Generative Grammar. Cambridge, MA: MIT Press.

Kamp, Hans and Uwe Reyle (1993): From Discourse to Logic. Dordrecht: Kluwer Academic Publishers.

Katz, Graham (1995): Stativity, Genericity and Temporal Reference. Ph. D. thesis, University of Rochester, Rochester, NY.

- (1997): Against Underlying States. In: Proceedings from the Twelfth Meeting of the Israeli Association of Theoretical Linguistics, Hebrew University, Jerusalem. Israeli Association of Theoretical Linguistics.

- (2000): Anti Neo-Davidsonianism: Against a Davidsonian Semantics for State Sentences. In: Carol Tenny and James Pustejovsky (eds.) Events as Grammatical Objects. Stanford, CA: CSLI Publications.

Katz, Jerrold and Jerry Fodor (1964): The Structure of Semantic Theory. In: Jerry Fodor and Jerrold Katz (eds.) The Structure of Language. Englewo od Cliffs, NJ: Prentice-Hall, Inc.

Klein, Wolfgang (1994): Time in Language. London: Routledge.

Kratzer, Angelika (1998): More Structural Analogies between Pronouns and Tenses. In: Proceedings of SALT VIII.

Krifka, Manfred (1989): Nominal Reference, Temporal Constitution and Quantification in Event Semantics. In: Renate Bartsch, Johan van Benthem, and Peter van Emde Boas (eds.) Semantics and Contextual Expression. Dordrecht: Foris Publications.

Löbner, Sebastian (1988): Ansätze zu einer Integralen Semantischen Theorie von Tempus, Aspekt, und Aktionsarten. In Veronika Ehrich and H. Vater (eds.) Temporalsemantik. Beiträge zur Linguistik der Zeitreferenz. Tübingen: Niemeyer.

Marantz, Alec (1999): Creating Words Above and Below Little v. MIT manuscript.

Moltmann, Friederike (1991): Measure Adverbials. Linguistics and Philosophy 14/6, 629-660.

Parsons, Terry (1985): Underlying Events in the Logical Structure of English. In: Ernest LePore and Brian McLaughlin eds.) Actions and Events: Perspectives on the Philosophy of Donald Davidson. Oxford: Blackwell.

- (1990): Events in the Semantics of English: A Study in Subatomic Semantics. Cambridge, MA: MIT Press.

Rochette, Annette (1990): The Selectional Properties of Adverbs. In: Papers from the 26th Regional Meeting of CLS. Chicago: Chicago Linguistics Society.

Sandstrøm, Gorel (1993): When-Clauses and the Temporal Interpretation of Narrative Discourse. Ph. D. thesis, University of Umea.

Thomason, Richard and Robert Stalnaker (1973): A Semantic Theory of Adverbs. Linguistic Inquiry 4/2, 195220.

Vendler, Zeno (1967): Linguistics in Philosophy. New York: Cornell University Press.

Vlach, Frank (1981): The Semantics of the Progressive. In: Philip Tedeschi and Annie Zaenen (eds.) Syntax and Semantics. Volume 14: Tense and Aspect, 271-292. New York: Academic Press.

Wyner, Adam (1994): Boolean Event Lattices and Thematic Roles in the Syntax and Semantics of Adverbial Modification. Ph. D. thesis, Cornell University. 
- (1998): A Discourse Theory of Manner and Factive Adverbials. In J. Hulstijn and A. Nijholt (eds.) The Proceedings of Twendial '98. Enschede, The Netherlands: University of Twente.

Zucchi, Alessandro (1993): The Language of Propositions and Events: Issues in the Syntax and the Semantics of Nominalization. Dordrecht: Kluwer

(1999): Incomplete Events, Intensionality and Imperfective Aspect, Natural Language Semantics. 7/2, 179-215.

- $\quad$ / Michael White (1996): Twigs, Sequences and the Temporal Constitution of Predicates. In: Proceedings of SALT VI. 